\title{
Taking it outside: A study of legal contexts and external whistleblowing in China and India
}

\author{
Sebastian Oelrich ${ }^{1,2}$ (D) Kimberly Erlebach ${ }^{3}$
}

Received: 21 February 2020 / Accepted: 17 April 2021 / Published online: 4 May 2021

(C) The Author(s) 2021

\begin{abstract}
Whistleblowing is regularly identified as corporate control mechanism to prevent and uncover fraud. We review and compare the legal situation for whistleblowers in the People's Republic of China and India. In a survey of 942 employees from private companies in both countries, we take a look at the status quo of whistleblowing system implementation, explore preference of channels to disclose fraud or corruption, and analyze under which conditions and what kind of employees prefer external over internal whistleblowing. We find that provisions for mandatory whistleblowing systems can be found in the law of both countries. In China in particular, protection is scattered across many different laws in the private sector. Indian companies seem to have systems in place more often, although this difference becomes smaller the larger the company. The general preference of internal over external channels is similar across countries. Our regression models suggest that external channels are preferred over internal ones when fear of retaliatory measures is higher, the company is smaller, and the whistleblower is female. In line with prior literature, the effect of fear of retaliation is moderated by gender: women are less influenced by retaliation. All in all, implementation of whistleblowing systems seems ubiquitous in both countries; legal protection and comprehensive measures to decrease retaliation are lacking. Additional implications of findings are discussed.
\end{abstract}

Keywords External whistleblowing · Corporate governance $\cdot$ China $\cdot$ India $\cdot$ Whistleblowing systems · Fraud · Whistleblowing legislation

Sebastian Oelrich

sebastian.oelrich@ovgu.de

1 Otto-von-Guericke-University Magdeburg, Universitaetsplatz 2, 39106 Magdeburg, Germany

2 Economy \& Crime Research Center, 06099 Halle, Germany

3 Martin-Luther-University Halle-Wittenberg, Halle, Germany 


\section{Introduction}

Whistleblowing is an effective tool in the fight against corruption, fraud, and misconduct in companies (Call et al., 2018; Wilde, 2017). Fraud is a major issue as it causes billions in damages annually (ACFE, 2020), only aggravated by large scandals such as Enron, WorldCom, or recently Wirecard. A common definition introduced by Near and Miceli $(1985,4)$ characterizes the behavior as "disclosure by organization members (former or current) of illegal, immoral and illegitimate practices under the control of their employers to parties and organizations that may be able to effect action." However, regulation is unevenly distributed across countries. The United States of America (US) and recently Europe introduced comprehensive whistleblowing laws aimed at whistleblowing protection (Mogielnicki, 2011; Oelrich, 2019). As a result, more and more companies introduce whistleblowing systems and channels inside the company.

Research has shown that much depends on the specific whistleblowing channel established and its characteristic - at least in hypothetical scenarios (e.g., Dhamija \& Rai, 2018; Park et al., 2008; Park \& Blenkinsopp, 2009). The predominant view there is that internal channels are preferred to external ones and that retaliation is a relevant factor in this decision process. Other research has focused on the relevance of laws for whistleblowing, discussing several legislative advances (Moberly, 2007; Mogielnicki, 2011; Oelrich, 2019). It is not surprising that much research focuses on the US, which led reforms worldwide with the introduction of the Sarbanes-Oxley Act (SOX) in 2002 and Dodd-Frank Act (DFA) in 2010. In contrast, research on whistleblowing laws and the whistleblowing process itself in Asian contexts is still in its infant stages. This is despite the fact that researchers have called for more inter- and cross-cultural research (i.e., Brown et al., 2014; Chwolka \& Oelrich, 2020; Gibeaut, 2006; Hartman et al., 2009; Park et al., 2008). In addition, much empirical research concerned with the whistleblowing process relies on student samples, which is criticized for not being realistic. This may be especially true when we are interested in channel use, especially internal vs external channels (Culiberg \& Mihelič, 2017; Mesmer-Magnus \& Viswesvaran, 2005).

China and India are the world's second and third largest economies, are important trade partners for many countries, and play crucial roles in many supply chains globally (The World Bank, 2020). It is therefore crucial for trade partners to be able to rely on effective corporate governance mechanisms of Chinese and Indian companies. Given documented widespread fraud and corruption in these countries (e.g., Transparency International, 2020), knowing how and if whistleblowing is a potential tool to encourage trust and compliance is essential for trade these relationships.

Our paper addresses this research gap and typical shortcomings of empirical studies with two major contributions. First, we comprehensively present, critically discuss, and compare the status quo of whistleblowing laws with a focus on the private sector in China and India. Second, we surveyed 942 employees in Chinese and Indian companies, evaluating the implementation and use of whistleblowing systems. We propose a logit regression and structural equation model (SEM) that explains why Chinese and Indian employees may choose external channels despite having internal options.

The rest of the paper is structured as follows. We first examine the legal landscape in China and India. Based on this and prior literature, we develop our hypotheses. This is 
followed by our sample description and methodology. We then conduct our analyses and present the results. In the last part, we critically discuss our findings, limitations, and future research.

\section{Legal provisions on whistleblowing protection and system implementation}

\section{Laws in PR China}

China has several regulations that deal with whistleblowing and whistleblower protection in the private sector. They can be categorized into two groups: general laws applicable to whistleblowing cases and specific regulations directly created for whistleblowers.

General laws that contain regulations applicable to whistleblowing in both the private and public sectors are the Constitution of the People's Republic of China (PRC), the Criminal Procedure Law of the PRC, and the Labor Law of the PRC. This last law for example contains protection provisions for whistleblowers. The employment relationship enjoys a certain degree of protection if the employee reports a misconduct that has come to their attention in the course of their employment relationship. This extends to protection from retaliation (Moy, 2018). If an employer takes measures against the whistleblower that lead to negative consequences because of the report, the employer may be fined and even criminal sanctions are possible (Art. 101 of the Labor Law of the PRC). If the whistleblower is dismissed, the court may, depending on the whistleblower's interest, order their reinstatement or award appropriate compensation (Freshfields, 2018).

In addition to these general protections, the 2014 Rules Dealing with Whistleblowing by the People's Procuratorate explicitly improved protection ( $\mathrm{Wu} \& \mathrm{Li}, 2015)$. Whistleblowers now have the right to view the status of their reports and request protection and rewards (Wu \& Li, 2015). In 2016 the Supreme People's Procuratorate, Ministry of Public Security, and the Ministry of Finance issued regulations that provide better protection and incentives for whistleblowers (van de Pol et al., 2016).

There are also specific laws which focus exclusively on the private sector in regard to whistleblowing protection. In 2008, China released the so-called China-SOX in order to provide legal protection to corporate whistleblowers from retaliation (Beller, 2011) and to establish and standardize internal controls (Lu \& Ma, 2017). Article 43 of the China-SOX contains rules on whistleblowing, including both regulations for the implementation of a whistleblowing system, as well as to protect whistleblowers. For example, it guarantees protection to whistleblowers through an anonymous reporting procedure (Beller, 2011). However, only companies listed on a domestic stock exchange are included. All other companies are not required, but encouraged, to implement such systems ( $\mathrm{Lu} \& \mathrm{Ma}, 2017$ ). China-SOX thus introduced comprehensive whistleblowing laws in the private sector.

In addition, there are several regulations related to the implementation of whistleblowing systems that only apply to specific industries or sectors. In the banking and insurance sector for example, regulations have been enacted that require companies to implement internal whistleblowing systems as part of their complaint management 
system (Freshfields, 2018). Some other sectors even introduced rewards for whistleblowing, such as in the tax, food, and drug industries (Freshfields, 2018).

\section{Laws in India}

Similar to China, there are also laws in India that apply to the field of whistleblowing. In 2004, India introduced the first whistleblowing regulations applicable only to the public sector with the Public Interest Disclosure and Protection of Informers Resolution (PIDPIR). This law was later amended by a law on whistleblowing, the "Whistleblowers Protection Act," which replaced the PIDIR and came into force in 2014 (Muttathil, 2018). The Whistleblower Protection Act was amended and supplemented in 2015 by the Whistleblower Protection Bill. None of these replacements affected the scope of the law, so it remains applicable to the public sector, only.

However, there are whistleblowing regulations that do apply to the private sector. In addition to PIDPIR, the Listing Agreement of the Securities and Exchange Board of India (SEBI) provides principles of Corporate Governance in Clause 49 of the Listing Agreement, which came into effect in its revised form in January 2006. And although these principles are mandatory for listed companies (Goel, 2014), it is obligatory to establish the whistleblowing systems stated in clause 49 Annexure ID (7): Clause 49 Annexure ID (7) states that all companies may establish and implement a system for reporting unethical conduct, fraud or suspected fraud, and violations of the companies' code of conduct or code of ethics. Existence of this system within a company is to be communicated and employees who report are to be protected against victimization and retaliation.

Private sector whistleblowing regulations can also be found in the Companies Act of 2013, containing the Indian company law. They are found in Section 177 (9) of the Companies Act and the Companies (Meetings of Boards and its Powers) Amendment Rules of 2014. Both regulations require the establishment of a system to receive reports of wrongdoings from employees. The regulation in Section 177 (9) of the Companies Act applies only to listed companies. In Rule 7 of the Companies (Meetings of Boards and its Powers) Amendment Rules the scope of companies that have to set up reporting systems is extended from Clause 49 of the Listing Agreement to companies that accept deposits from the public and companies that have accepted loans from banks and public financial institutions in excess of fifty crore rupees (approximately 7.1 million US dollars). Both regulations provide protection against the victimization of whistleblowers (Companies Act, Sec. 177 (10)/Rule 7 of the Companies (Meetings of Boards and its Powers) Amendment Rules). How the protection is to be provided, however, is not defined. There are no indications on how protection is guaranteed or specifically designed. The security measures are completely dependent on the guidelines drawn up by the companies themselves (Giriprakash, 2019). Contrary to Clause 49 of the Listing Agreement, rules provided by these regulations in regard to whistleblowing are mandatory.

\section{Comparison of Chinese and Indian laws}

In both countries, there are regulations, both for the public and private sector, which have been specially designed for whistleblowers. In China, in addition to these specific 
laws, some general rules may also be applied to whistleblowing, in particular provisions in the labor and criminal law.

As our focus is specifically on the private sector, we find that both countries can claim to have comprehensive whistleblowing regulations applicable to listed companies. However, there are no comprehensive regulations for the private sector in either country. In contrast to India, China has further regulations that regulate whistleblowing in individual areas in the private sector. This leads to a fragmentary condition and seems not very transparent. In contrast, the existing laws in India are very transparent, even if they only cover a limited area. A distinction should be made between laws that provide the establishment of whistleblowing systems and regulations that protect whistleblowers. These two aspects are regulated under the China-Sox in China. In contrast, the Company Act in India regulates protection of whistleblowers less explicitly. Thus, in comparison, China guarantees more comprehensive protective measures for whistleblowers.

\section{Hypotheses}

Although whistleblowing is generally seen as an effective corporate governance mechanism to discipline organizations (ACFE, 2020; Call et al., 2018; Wilde, 2017), there are controversial findings in the literature as to what constitutes an effective whistleblowing system (Culiberg \& Mihelič, 2017). A point prior studies in several countries unanimously agree is that people prefer internal over external channels (e.g., Dhamija \& Rai, 2018; Miceli \& Near, 2002; Nayir \& Herzig, 2012; Park et al., 2008). Only after such an internal report did not solve the issue are external channels utilized (Grant, 2002; Nayir \& Herzig, 2012; Near \& Miceli, 1985). Our main research goal is to understand why employees in China and India choose external channels over internal options. That is, why would an employee choose to report fraud or corruption to an outside agency if they could also report the misconduct to a designated internal one?

\section{Fear of retaliation}

Fear of retaliatory actions have been found to severely impact the decision process of whistleblowers. In general, studies find a negative influence of retaliation on whistleblowing, as Culiberg and Mihelič (2017) thoroughly discuss in their literature review. In more detail, Dhamija and Rai (2018) for example find that fear of retaliation has a negative impact on internal whistleblowing for Indian students. ${ }^{1}$ Conversely, it may foster the use of external channels. This is in line with major scandals in India, in which whistleblowers even paid disclosure with their lives, which may increase reluctance to disclose a wrongdoing internally (Gupta, 2015). Oelrich (2019) uses a sample of German business students to show that the impact of negative consequences is stronger than the incentive of financial reward systems for external whistleblowing. Rehg et al. (2008) also show that retaliation is positively associated with external

\footnotetext{
${ }^{1}$ They also analyze external whistleblowing intention. However, they were unable to find any relevant factor in external whistleblowing intentions (Oelrich, 2020).
} 
channel use over internal disclosure in a US sample. We therefore assume that fear of retaliation is positively associated with external channel use.

H1: Fear of retaliation has a positive effect on use of an external channel over an internal one.

\section{Company size}

Since most research relies on student samples and hypothetical scenarios, few studies exist that are able to account for company specific factors. In contrast, we surveyed actual employees (for a discussion, see for example Mesmer-Magnus \& Viswesvaran, 2005 or Culiberg \& Mihelič, 2017) and are thus able to assess the impact of several variables linked to the organization. We therefore draw on our review of whistleblowing laws in China and India in the previous chapter to develop our hypothesis. It is mandatory for many large companies to establish whistleblowing systems in both China and India. Larger companies are also more likely to be subject to international regulation and thus governance mechanisms from countries with (more) stringent whistleblowing directives, especially US legislation. Thus, established compliance systems in larger companies are more likely to be scrutinized by national and international authorities and stakeholders, including enforcement bodies, investors, customers and other companies along the supply chain. It is therefore not far stretched to assume that larger companies have better or more professional internal governance systems in place due to external pressure, in which employees place more trust than would be the case in smaller firms. Employees in larger firms should therefore place more trust in the formal channels established, whereas employees in smaller firms might doubt their effectiveness and instead turn towards external channels. Especially given the negative experiences and scandals of whistleblowers in India and China, less trust in an internal channel would result in use of an external one. Another point can be made for the connection between company size and feasibility of anonymity. In smaller firms, it is easier to uncover the identity of a whistleblower. Certain information can only reach a limited number of employees, and thus, tips on possible fraud and corruption can only originate from a small circle of people. As such, we hypothesize that employees in smaller firms are more likely to use external channels, whereas employees in larger firms would trust and thus prefer internal channels.

H2: Employees in larger companies are less likely to use an external channel over an internal one.

\section{Gender}

Sociodemographic factors produced mixed results across several studies. In particular, results on gender show that females are less likely to choose external channels on the one hand (Sims \& Keenan, 1998) and more likely on the other (Rehg et al., 2008). 
Other studies found no influence of gender on whistleblowing in general (MesmerMagnus \& Viswesvaran, 2005 or Culiberg \& Mihelič, 2017 for an overview). Given that studies that explicitly measured external whistleblowing in connection to retaliation settings found a positive effect for females (Rehg et al., 2008), we assume similar effects to be present in our sample. We agree with Rehg et al. (2008) that females place less trust in corporate governance mechanisms and fear negative consequences for their career. Given that women still face more disadvantages on the job than their male colleagues, they might be less inclined to turn to internal authorities and instead are more likely to choose an external response.

H3: There is a direct effect of gender on external channel use. Females are more likely than males to choose external channels over internal ones.

In addition to this direct effect, we assume there to a moderating effect. Rehg et al. (2008) found that females experience retaliation more often and more severely. Thus, gender should moderate the effect of fear of retaliation on whistleblowing channel use. Being female alone exposes one to an increased retaliation likelihood in general. This might be even more severe in countries with more traditional gender roles, such as China and India (for gender discrimination in these contexts, see OECD, 2019). Thus, female employees are less severely influenced by fear of retaliation in their decision whether to report externally or not. As stated above, they would have an a priori higher likelihood to report externally. This is in part because they would anticipate being retaliated against more often and severely, regardless of channel used. However, an increase in retaliation should nonetheless lead to an increase in external channel preference, if not as strongly as it might influence their male counterparts.

H4: The effect of fear of retaliation on external over internal channel use is moderated by gender. The effect of retaliation is diminished for female compared to male employees.

\section{Control variables}

Other sociodemographic factors such as age, tenure, or position have yielded conflicting results (Culiberg \& Mihelič, 2017; Mesmer-Magnus \& Viswesvaran, 2005). We include these aspects as controls, as few studies use actual workforce as their sample. Culiberg and Mihelič (2017) review recent whistleblowing studies and conclude that sociodemographic factors in general have little influence on whistleblowing. Sims and Keenan (1998) find no effect of age and tenure, and Cassematis and Wortley (2013) find no significant influence for age and education. Contradicting results are found by Ahmad (2011) for age and tenure in internal whistleblowing intentions and by Dworkin and Baucus (1998) for tenure. The same holds true for findings using a sample of Indian students (Dhamija \& Rai, 2018).

In addition, we survey employees from different countries, which might introduce issues of cross-cultural comparability. We therefore include a country dummy variable as additional control. We do not state hypotheses for control variables. 


\section{Research design}

\section{Sample and data gathering}

Whistleblowing studies are predominantly conducted on student samples, limiting their applicability to real world scenarios. It also implies that company characteristics as antecedents are rarely evaluated. To address this, we conducted an anonymous telephone-based survey, in line with similar research on whistleblowing (Rothschild \& Miethe, 1999). Respondents were informed that the study was conducted by a major German university, and answers would be used for research purposes only and were ensured anonymity. The questions were translated using back-to-back translation processes, in order to ensure correct translations. The English version used throughout this paper is a loose translation of the original questionnaire, as we never conducted this research in an Englishspeaking country. The interviewees were chosen randomly. ${ }^{2}$ A pre-requisite for each telephone interview was a minimum age of 21, at least a bachelor's degree or equivalent, and employment in a private company of at least 100 employees in size. $^{3}$ Interviews lasted for $20 \mathrm{~min}$ on average and were conducted in the respective language in each country. Our sample is therefore a random, quasirepresentative survey of companies across both countries.

We conducted a pre-test of $n=25$ in each country. Non-substantial changes were made, which resulted in a clearer framing of several questions. We gathered data from 475 respondents in China and 467 in India, resulting in a final sample of $N=942$ responses, excluding pre-test data.

The surveyed were asked several questions regarding whistleblowing, corporate governance, and corruption and fraud aspects within their company and in their countries in general. In this study, we focus on aspects concerned with whistleblowing as corporate governance instrument. Sociodemographic and company characteristics were elicited at the end of each interview.

Descriptive results are given in Table 1 together with the respective coding for further analysis. In India, we have a significantly lower number of female respondents. Taken together, almost $40 \%$ of respondents are female. In both countries, a majority of respondents have a position in higher management, which is in line with age demographics, as most respondents are between 30 and 50 years and worked in their respective companies for several years already. A majority of the surveyed companies in India are listed on a stock exchange (80.6\%), while only 1 in 5 companies in China is listed (19.4\%). The sample characteristic distributions are comparable on other aspects across countries.

\footnotetext{
${ }^{2}$ As common in such surveys, the interviewee phone numbers are randomly generated by using a number root that belongs to a certain region or city. Subsequent digits in the phone number are added by a machine algorithm. This is all done by a professional third party that conducts these interviews.

${ }^{3}$ Companies smaller than 100 employees often do not have whistleblowing systems in place, which would have severely limited our study design.
} 
Table 1 Sociodemographic and company characteristics

\begin{tabular}{|c|c|c|c|c|c|c|}
\hline \multirow[t]{2}{*}{ Variables (variable coding) } & \multicolumn{2}{|c|}{ China } & \multicolumn{2}{|c|}{ India } & \multicolumn{2}{|c|}{ Overall } \\
\hline & $n$ & $\%$ & $n$ & $\%$ & $n$ & $\%$ \\
\hline Total & 475 & 100 & 467 & 100 & 942 & 100 \\
\hline \multicolumn{7}{|l|}{ A. Gender } \\
\hline Male (0) & 209 & 44.0 & 373 & 79.9 & 582 & 61.8 \\
\hline Female (1) & 266 & 56.0 & 94 & 20.1 & 360 & 38.2 \\
\hline \multicolumn{7}{|l|}{ B. Position } \\
\hline Secretary (1) & 61 & 13.5 & 1 & 0.5 & 62 & 9.3 \\
\hline Assistant (2) & 33 & 7.3 & 35 & 16.3 & 68 & 10.2 \\
\hline Lower management (3) & 123 & 27.3 & 43 & 20.0 & 166 & 24.9 \\
\hline Middle/upper management (4) & 184 & 40.8 & 95 & 44.2 & 279 & 41.9 \\
\hline Senior/top management (5) & 50 & 11.1 & 41 & 19.1 & 91 & 13.7 \\
\hline \multicolumn{7}{|l|}{ C. Age } \\
\hline $21-25(1)$ & 1 & 0.2 & 11 & 2.4 & 12 & 1.3 \\
\hline $26-29(2)$ & 91 & 19.2 & 64 & 13.7 & 155 & 16.5 \\
\hline $30-39(3)$ & 243 & 51.2 & 167 & 35.8 & 410 & 43.5 \\
\hline $40-49$ (4) & 124 & 26.1 & 193 & 41.3 & 317 & 33.7 \\
\hline $50-59(5)$ & 15 & 3.2 & 31 & 6.6 & 46 & 4.9 \\
\hline 60 or older (6) & 1 & 0.2 & 1 & 0.2 & 2 & 0.2 \\
\hline \multicolumn{7}{|l|}{ D. Tenure } \\
\hline Less than 2 years (1) & 53 & 11.2 & 29 & 6.2 & 82 & 8.7 \\
\hline $2-3$ years $(2)$ & 136 & 28.7 & 105 & 22.5 & 241 & 25.6 \\
\hline $4-5$ years $(3)$ & 132 & 27.8 & 205 & 43.9 & 337 & 35.8 \\
\hline $6-7$ years $(4)$ & 53 & 11.2 & 98 & 21.0 & 151 & 16.0 \\
\hline $8-9$ years $(5)$ & 31 & 6.5 & 18 & 3.9 & 49 & 5.2 \\
\hline More than 9 years (6) & 69 & 14.6 & 12 & 2.6 & 81 & 8.6 \\
\hline \multicolumn{7}{|l|}{ E. Company size } \\
\hline 101 to $250(1)$ & 181 & 38.1 & 62 & 13.3 & 243 & 25.8 \\
\hline 251 to 499 (2) & 149 & 31.4 & 56 & 12.0 & 205 & 21.8 \\
\hline 500 to $999(3)$ & 79 & 16.6 & 164 & 35.1 & 243 & 25.8 \\
\hline 1000 to 4999 (4) & 48 & 10.1 & 146 & 31.3 & 194 & 20.6 \\
\hline 5000 to $10,000(5)$ & 9 & 1.9 & 18 & 3.9 & 27 & 2.9 \\
\hline More than $10,000(6)$ & 9 & 1.9 & 21 & 4.5 & 30 & 3.2 \\
\hline
\end{tabular}

Numbers in brackets are coding used for subsequent bivariate and multivariate analyses

\section{Variables and constructs}

\section{Internal and external whistleblowing channels}

In our survey, we asked respondents whether they knew about whistleblowing channels established within their company. We distinguish between 4 different kinds of whistleblowing systems: (1) internal ombudsperson, such as a compliance officer, or 
supervisor; (2) a telephone-based system; (3) a web- or intranet-based system; (4) and an external agency, such as regulator, authority, or external ombudsperson. While the first three channels are internal, the last one qualifies as an external channel (Lewis, 2007). Descriptive results of the implementation of these channels are given in Fig. 1 by country and company size.

We see that Indian companies seem to have more whistleblowing channels established within as well as outside the company overall. The internal ombudsperson seems less frequently implemented in China compared to other internal channels in this country. However, for the largest companies, these differences in channel implementation across countries disappear. Some of the differences between countries could be attributable to the fact that $80 \%$ of Indian employees surveyed work for a company listed on a stock exchange and thus companies that are subject to more stringent whistleblowing regulation. These descriptive results are also in line with our analysis of mandatory system implementation according to regulation in India and China, as we found that in general, system implementation would be more likely for large Indian companies.

There is a clear trend in the data the larger the company, the more likely any of the different whistleblowing channels is established and known to the respondents. We also find that especially in China the implementation of web-based systems seems to be the dominant approach in larger companies, in line with our analysis of legal requirements.

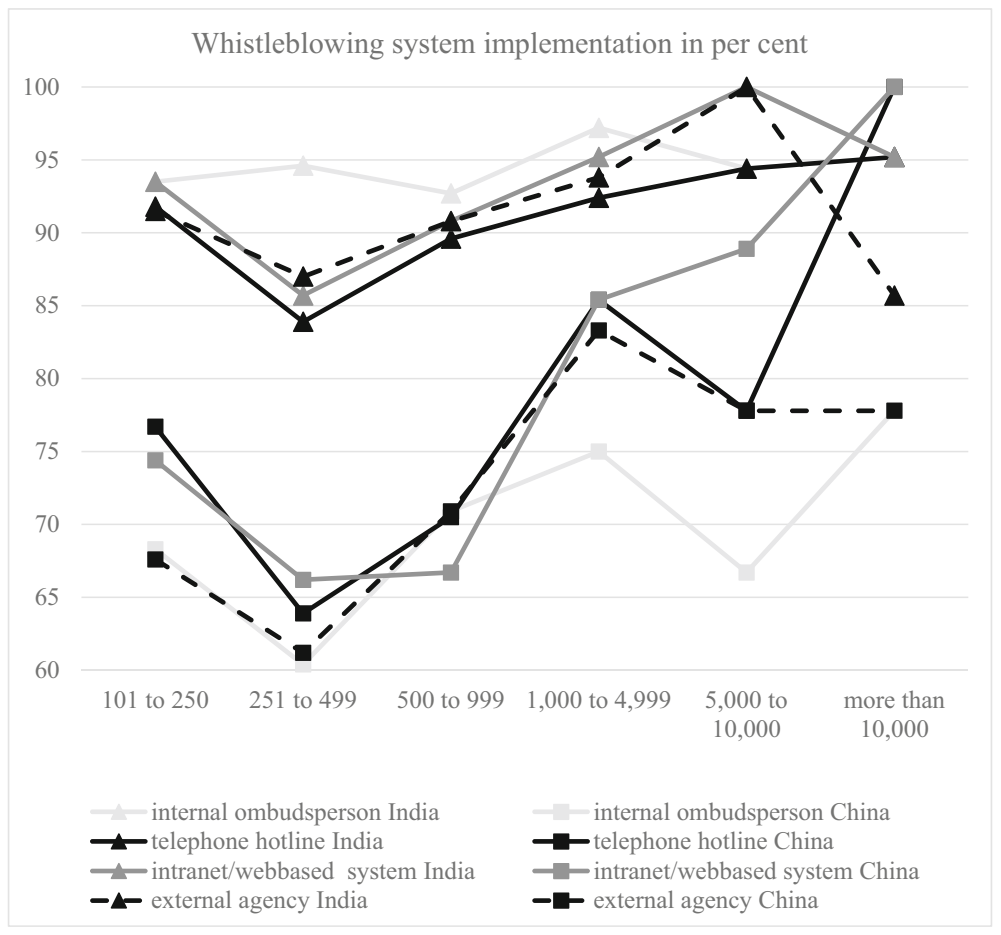

Note. Triangle indicates Indian companies, square indicates responses from China, straight lines are for internal channels and dotted lines show external channels.

Fig. 1 Whistleblowing system implementation in per cent 


\section{Whistleblowing experience and intention}

Next, we asked respondents about their experiences with situations in which they observed a severe case of fraud or corruption. ${ }^{4}$ Overall, $34.3 \%$ of respondents had such an experience in their current workplace at some point in the past. Although this number seems quite high, it is in line with other reports from around the world (e.g., ACFE, 2020).

We then asked whether they reported this suspicion" with "yes" and "no" as possible answers. If they never had such an experience, respondents were given a hypothetical scenario in which corruption was taking place in their company, which they observe. ${ }^{6}$ Their intention to whistle blow was elicited on a 5-point Likert answering format with 1 (very unlikely) to 5 (very likely). In the real case, the "yes" answer is coded as 5 , similar to "very likely." "No" is coded as 1, in line with "very unlikely" in the hypothetical case. Figure 2 shows an overview of the responses, where very likely/yes (5) and rather likely (4), and very unlikely/no (1) and rather unlikely (2) are grouped.

We find that although we asked about severe cases of fraud and corruption, only about half of the respondents did/would report their suspicion. In fact, one third of respondents would not report their suspicions at all, while the rest was indecisive. In regard to country differences, we find that respondents from India $(M=3.46, S D=$ $1.65)$ are slightly more likely to blow the whistle than respondents from China $(M=$ $3.00, S D=1.35), t(831.96)=-4.411, p<.000 .^{7}$

\section{Dependent variable: External channel preference}

In this study, we are interested in why people who blow the whistle choose an external channel over any internal option. There are two preconditions in order to measure this. First, one has to have the intention to whistle blow, and second, one needs to have the option. In the following analysis, we therefore exclude all responses from people who had no intention to whistle blow (very unlikely/no, rather unlikely) and include only those who indicated that they were aware of internal and external channels in their work environment. We split our sample so that we only include employees with a relatively high whistleblowing intention $(\geq 3)$ or actual behavior. First, we pool responses on whistleblowing intention and actual whistleblowing, as prior research suggested that the differences are not substantial, as long as effect sizes are interpreted with caution (Oelrich, 2021). As we are more interested in effect directions, this is, according to Oelrich (2021), a valid approach. Second, we only include employees who had all channels as options, to control for availability effects. ${ }^{8}$ Our sample is thus reduced to 451 valid responses. Our dependent variable, external whistleblowing, is therefore a binary response with 1 as use of an external channel and 0 as use of an internal channel.

\footnotetext{
${ }^{4}$ In their respective language, we asked: "Have you ever had a suspicion of a serious economic crime such as fraud or corruption in the working environment of your current company?"

5 "Did you report your suspicions?"

6 "Let us assume that you become aware of a significant case of corruption in your company. It is not an option for you to talk to your supervisor and other colleagues about this. Would you report this suspicion?" ${ }^{7}$ In more detail, the difference is only significant for the behavior sample $(t(321)=-7.158, p<.000)$ and not for the intention sample $(t(408.072)=1.516, p=.130)$.

${ }^{8}$ For example, otherwise a person may only be inclined to report externally, because the company did not establish any internal channel or only one channel which for some reason is not trusted by the employee.
} 


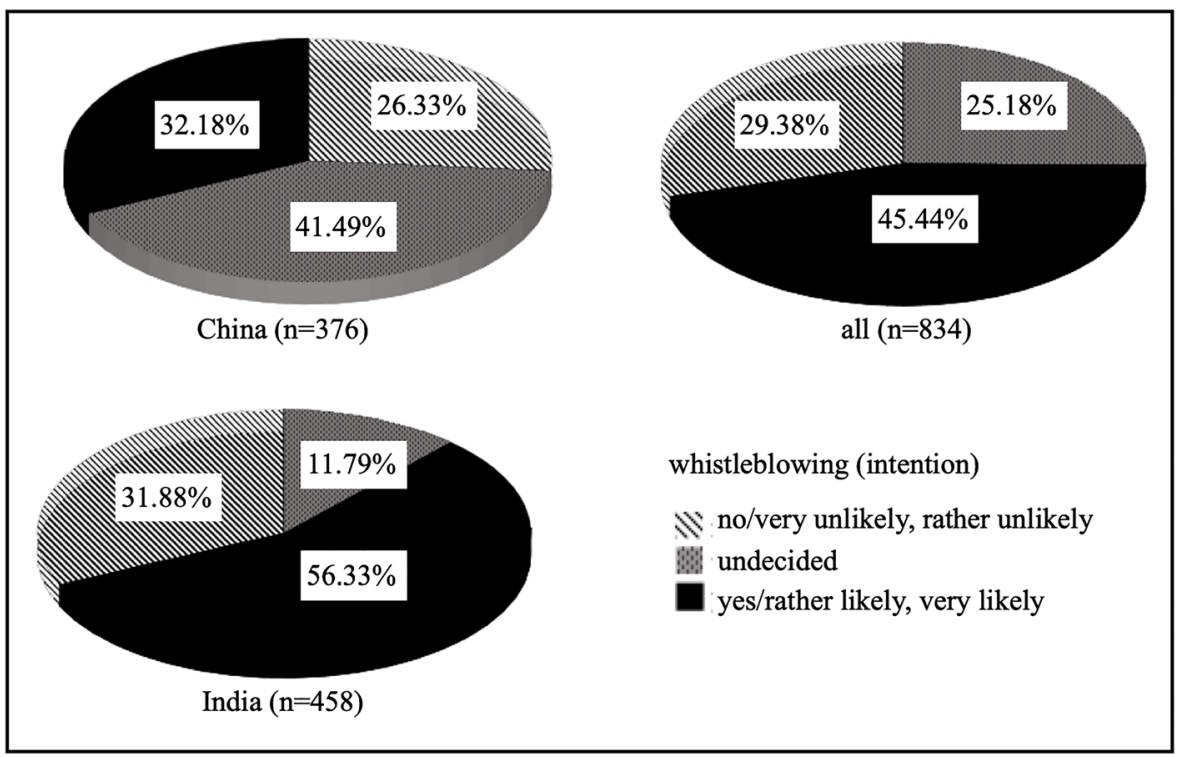

Note. Whistleblowing (intention) for each country as well as overall. Answers very likely/yes and rather likely, and very unlikely/no and rather unlikely are grouped, respectively.

Fig. 2 Whistleblowing (intention) of Chinese and Indian employees

Prior studies in several countries unanimously conclude that people prefer internal over external channels (Dhamija \& Rai, 2018; Miceli \& Near, 2002; Nayir \& Herzig, 2012; Park et al., 2008). Only after such an internal report did not solve the issue are external channels utilized (Grant, 2002; Nayir \& Herzig, 2012; Near \& Miceli, 1985). This is something that we also observe. We use the non-parametric Cochran's $Q$ test (Cochran, 1950) on multiple group comparisons $(k>2$, here: $k=4)$ and binary responses to account for all possible channel comparisons simultaneously. Results are given in Table 2 .

We find that the internal ombudsperson is preferred to the external agency in both countries, while the preference for internal ombudsperson over telephone and webbased internal channels is only significant in India. In both countries, there is no difference in web-based and telephone channel preference.

In order to test for differences in channel preference between countries, we use Pearson chi-square tests. Preferences across countries differ only in regard to internal ombudsperson $\left(\chi^{2}(1)=51.676, p<.000\right)$ and external agency $\left(\chi^{2}(1)=29.868\right.$, $p<.000)$. In both cases, Indian employees have a higher preference for these channels than Chinese employees. In contrast, the differences for telephone $\left(\chi^{2}(1)=\right.$ 2.080, $p=.149)$ and web-based systems $\left(\chi^{2}(1)=0.042, p=.837\right)$ seem to be similar.

\section{Fear of retaliation}

Respondents were also asked about fears associated with reporting the case. ${ }^{9}$ In particular, we asked about three aspects: "disadvantages on job," "lack of

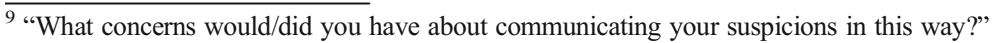


Table 2 Related samples Cochran's $Q$ test results

\begin{tabular}{|c|c|c|c|c|}
\hline \multirow[t]{2}{*}{ Comparison of whistleblowing channel preferences } & \multicolumn{2}{|l|}{ India } & \multicolumn{2}{|l|}{ China } \\
\hline & $\begin{array}{l}\text { Std. test } \\
\text { statistic }\end{array}$ & $\begin{array}{l}\text { adj. } p \\
\text { value }\end{array}$ & $\begin{array}{l}\text { Std. test } \\
\text { statistic }\end{array}$ & $\begin{array}{l}\text { adj. } p \\
\text { value }\end{array}$ \\
\hline Internal ombudsperson vs external agency & -4.632 & $<.000 * * *$ & -3.170 & $.009 * *$ \\
\hline Internal ombudsperson vs telephone-based & -7.782 & $<.000^{* * *}$ & -1.585 & .678 \\
\hline Internal ombudsperson vs web-based & -7.875 & $<.000 * * *$ & -.264 & 1.000 \\
\hline Telephone vs web-based & -.093 & 1.000 & -1.321 & 1.000 \\
\hline External agency vs telephone & -3.150 & $.010 *$ & -1.585 & .678 \\
\hline External agency vs web-based & -3.243 & $.007 * *$ & -2.905 & $.022 *$ \\
\hline
\end{tabular}

Related samples Cochran's $Q$ test. Overall significant difference in preferences in both China $(Q(3)=12.663$, $p=.005)$ and India $(Q(3)=82.245, p<.000)$. Each row tests the null hypothesis that the sample 1 and 2 distributions are the same. Asymptotic significances (two-sided tests) are displayed. Significance values have been adjusted by the Bonferroni correction for multiple tests

$* p<.05, * * p<.01, * * * p<.001$

confidentiality or anonymity," and "doubts as to whether case would be thoroughly investigated," measured on a 5-point Likert answering format with 1 (not at all) to 5 (very much). Internal consistency reliability measured with Cronbach's alpha $\alpha=0.764^{10}$ is high. All three items are grouped as mean value "fear of retaliation."

\section{Other variables in model}

All other variables are elicited as single items within the survey. Their respective coding for regression analysis is given in Table 1 . The country variable is coded as country dummy with 0 for India and 1 for China. Gender is also coded as binary variable with 0 as male and 1 as female.

\section{Methodological approach}

Our dependent variable is a binary choice (internal or external channel); thus, binary logistic regression analysis is used as the primary method. As an additional control, we corroborate our findings with structural equation modeling (SEM), in particular the partial least squares approach (PLS). It is commonly used in business research and described as a "silver bullet" (Hair et al., 2011). PLS outperforms other approaches, such as covariance-based SEM when sample sizes are relatively small and data is not normally distributed. It also handles the use of constructs well (Hair et al., 2011).

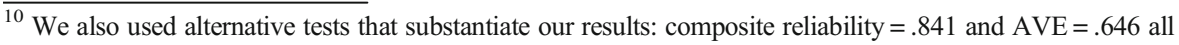
indicate a very good fit of the construct (Hair et al., 2017).
} 


\section{Results}

\section{Logit regression results}

Correlations are shown in Table 3 and results of the multivariate logit regression are given in Table 4, model 1. The overall regression is significant $(p=.001)$ and the model's explanatory power of the dependent variable is satisfactory with Nagelkerkes $R^{2}=0.118$ and Cox and Snell $R^{2}=0.087$.

Fear of retaliatory measures has a significant positive effect $(\beta=-1.607$, one tailed $p=.017$ ) on external channel preference over internal channels, as proposed in hypothesis 1 . Thus, higher fear of retaliation leads employees to choose external over internal channels more often, when wanting to blow the whistle. Company size on the other hand has a negative effect on external whistleblowing $(\beta=-0.299$, one tailed $p=.001$ ). The larger the company an employee works for, the less likely that they would choose an external over an internal channel. In other words, the preference for internal channels is higher in large companies, whereas employees in smaller companies more often choose external whistleblowing. This is in line with hypothesis 2.

The direct effect of gender is not statistically significant in this model (onetailed $p=.118$ ); thus, the direct effect difference between male and female employees needs to be rejected according to this initial model (hypothesis 3). We also hypothesized a moderation effect of gender on fear of retaliation, which we modeled as multiplicative term in the logistic regression with gender $\times$ fear of retaliation. This effect is significant $(\beta=-0.452$, one - tailed $p=.047)$, suggesting that being female reduces the positive effect of fear of retaliation on external channel use. This is in line with our hypothesis 4 and we interpret the meaning of this moderation effect in detail in the discussion section.

The control variables age and position are not significant (two - tailed $p>.05$ ). However, tenure seems to have a direct positive influence on external channel use $(\beta=-0.452$, two - tailed $p=.020)$, suggesting that working for company for a longer time increases the likelihood for employees to choose an external over internal channel.

In a second logistic regression (model 2, Table 4), we introduce a binary country dummy to test for robustness of the effects across both subsamples. We find that this country dummy is not significant (two - tailed $p=.458$ ), and therefore indicates that our results are not driven by differences across both countries in the analysis. All other effects are similar to the base model (model 1, Table 4).

We refrain from interpreting the effect sizes, especially odds ratios for the predictors, as we pooled hypothetical and real decisions to increase the usable sample. When using intention data, effect sizes, opposed to significance and direction of effect, should not be interpreted, as they might be skewed (Oelrich, 2021).

\section{Robustness checks}

As a first robustness check, we apply bootstrapping as a resampling procedure with $n=$ 1,000 to our logistic regression models 1 and 2 in Table 4 . The results do not change significantly from the values reported in Table 4. 


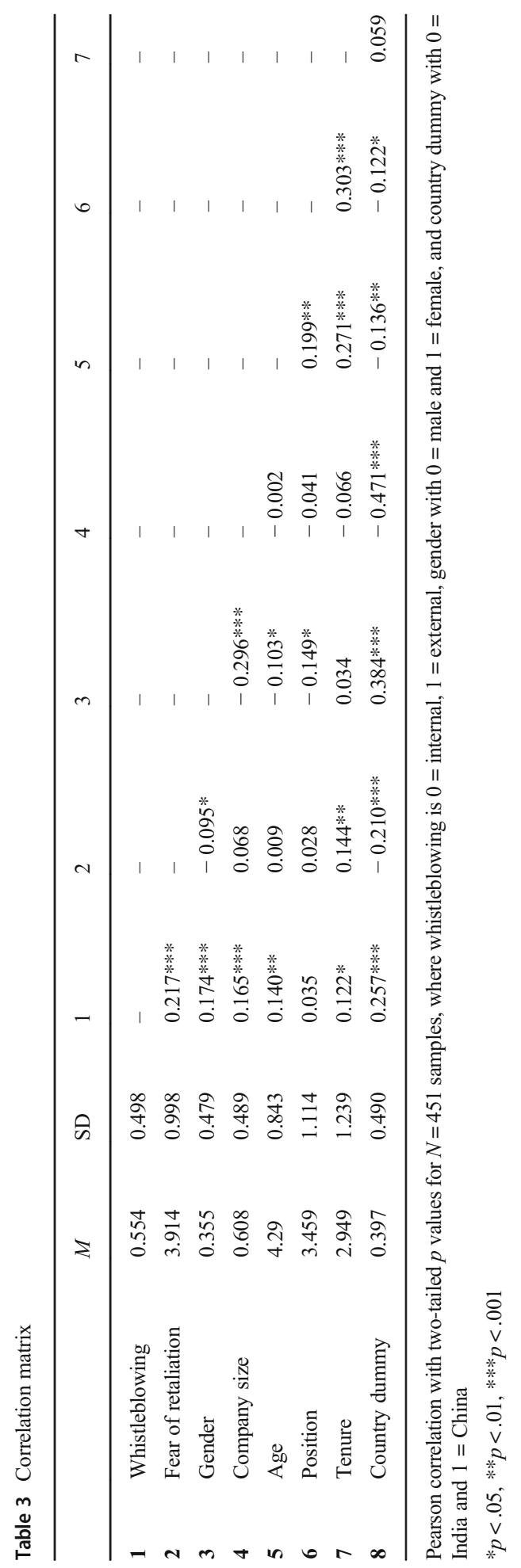


Table 4 Logit regressions on whistleblowing

Dependent variable: whistleblowing $0=$ internal, $1=$ external

\begin{tabular}{|c|c|c|c|c|c|c|c|c|}
\hline & \multicolumn{4}{|l|}{ Model 1} & \multicolumn{4}{|l|}{ Model 2} \\
\hline & $\beta$ & SE & $p$ value & $e^{\beta}$ & $\beta$ & SE & $p$ value & $e^{\beta}$ \\
\hline Constant & -1.607 & 1.151 & .163 & 0.200 & -1.352 & 1.204 & .262 & 0.259 \\
\hline Fear of retaliation & $0.439 *$ & 0.206 & $.017^{\mathrm{a}}$ & 1.551 & $0.426^{*}$ & 0.207 & $.020^{\mathrm{a}}$ & 1.530 \\
\hline Gender & 1.234 & 1.038 & $.118^{\mathrm{a}}$ & 3.433 & 1.286 & 1.045 & $.109^{\mathrm{a}}$ & 3.617 \\
\hline Company size & $-0.299 * *$ & 0.099 & $.001^{\mathrm{a}}$ & 0.741 & $-0.319 * *$ & 0.103 & $.001^{\mathrm{a}}$ & 0.727 \\
\hline Age & 0.060 & 0.152 & .693 & 1.062 & 0.053 & 0.152 & .726 & 1.055 \\
\hline Position & -0.077 & 0.124 & .535 & 0.926 & -0.088 & 0.125 & .483 & 0.916 \\
\hline Tenure & $0.227 *$ & 0.097 & .020 & 1.254 & $0.253 *$ & 0.098 & .017 & 1.265 \\
\hline gender $\times$ fear of retaliation & $-0.452 *$ & 0.269 & $.047^{\mathrm{a}}$ & 0.636 & $-0.447^{*}$ & 0.270 & $.049^{\mathrm{a}}$ & 0.640 \\
\hline Country dummy & & & & & -0.224 & 0.301 & .458 & 0.800 \\
\hline df & 7 & & & & 7 & & & \\
\hline$\chi^{2}$ & 25.496 & & & & 26.048 & & & \\
\hline$p$ value & .001 & & & & .001 & & & \\
\hline Nagelkerkes $R^{2}$ & 0.118 & & & & 0.121 & & & \\
\hline Cox and Snell $R^{2}$ & 0.087 & & & & 0.089 & & & \\
\hline$N$ & 451 & & & & 451 & & & \\
\hline
\end{tabular}

Model 1 predicts $68.3 \%$ of cases correctly, model $265.8 \%$ overall

${ }^{a}$ One-sided $p$ value, as hypothesis was directional

$* p<.05, * * p<.01, * * * p<.001$

Second, we use PLS SEM modeling to test our hypotheses further. There are several advantages of structural models over logistic regression analysis. We are able to control for several mediation effects and can utilize a superior modeling of latent constructs, such as fear of retaliation compared to the mean-score procedure used previously (Hair et al., 2018). It is plausible that age, position in a company, and tenure are correlated (see correlation Table 2) and might influence each other. In particular, we model a direct effect of age on position and tenure, as well as of tenure on position. All other relationships are retained from the logistic models, including the country dummy.

We establish discriminant validity with heterotrait-monotrait ratio of correlations (HTMT). All cross-loadings are far below the recommended thresholds of 0.90 (Hair et al., 2017, 61). There is also no issue of collinearity between variables, given by VIF values below 5 (Hair et al., 2017, 125). PLS SEM utilizes a non-parametric approach. In order to evaluate significances of paths, a bootstrapping procedure is implemented and results are reported as bias-corrected bootstrap values, obtained by $n=5,000$ bootstrap resamples. The moderation effect of gender on fear of retaliation is calculated as unstandardized product indicator, which yields more accurate results but needs more computing power (Hair et al., 2017). The dependent variable external whistleblowing ${ }^{11}$ is explained

\footnotetext{
${ }^{11}$ Our dependent variable, external whistleblowing, is a binary response (yes/no). Where "no" means that respondents would use/used an internal channel. PLS SEM is found to handle these types of variables under certain conditions well (Bodoff \& Ho, 2016).
} 
Table 5 PLS SEM with moderated mediation analysis

\begin{tabular}{llllll}
\hline Structural path & Coeff. B & SD & $p$ value & $95 \%$ CI BC \\
\hline A. Direct effects & & & & & \\
Fear of retaliation & $\rightarrow$ External WB & $0.240^{* *}$ & 0.094 & $.005^{\mathrm{a}}$ & {$[0.109,0.396]$} \\
Gender & $\rightarrow$ External WB & $0.367^{*}$ & 0.219 & $.047^{\mathrm{a}}$ & {$[0.098,0.769]$} \\
Company size & $\rightarrow$ External WB & $-0.201^{* * *}$ & 0.059 & $<.000^{\mathrm{a}}$ & {$[-0.297,-0.104]$} \\
Age & $\rightarrow$ External WB & 0.026 & 0.064 & .685 & {$[-0.101,0.150]$} \\
Position & $\rightarrow$ External WB & -0.045 & 0.061 & .465 & {$[-0.160,0.081]$} \\
Tenure & $\rightarrow$ External WB & $0.153^{*}$ & 0.067 & .022 & {$[0.027,0.291]$} \\
Country dummy & $\rightarrow$ External WB & -0.050 & 0.067 & .453 & {$[-0.179,0.080]$} \\
B. Mediation effects & $\rightarrow$ Position & $0.118^{*}$ & 0.058 & .041 & {$[0.004,0.227]$} \\
Age & $\rightarrow$ Tenure & $0.303^{* * *}$ & 0.051 & $<.000$ & {$[0.201,0.401]$} \\
Age & $\rightarrow$ Position & $0.267^{* * *}$ & 0.057 & $<.000$ & {$[0.148,0.373]$} \\
Tenure & $\rightarrow$ External WB & $-0.239^{*}$ & 0.125 & $.028^{\mathrm{a}}$ & {$[-0.441,-0.071]$} \\
C. Moderation effects & & & & &
\end{tabular}

PLS SEM with bootstrap $n=5000$, path weighting scheme and case-wise deletion of missing values. Binary dependent variable for whistleblowing with $0=$ internal and $1=$ external whistleblowing. $\mathrm{CI} \mathrm{BC}=$ confidence interval bias corrected. Overall model is significant with $p<.000$. Dependent variable whistleblowing goodness of fit: $R^{2}=.131$ and adj. $R^{2}=.105$. Gender is coded $0=$ male, $1=$ female. Country dummy with 0 = India, 1 = China

a One-tailed results are reported, as the hypothesis was directional

$* p<.05, * * p<.01, * * * p<.001$

comparably well with an $R^{2}=0.131\left(\operatorname{adj} . R^{2}=0.105\right)$ and the model is significant $(p<.000)$. Results are given in Table 5.

Similar to the logistic model, we find that fear of retaliation is a positive contributor in the decision to blow the whistle externally $(\beta=0.240$, one - tailed $p=.005)$, company size has a negative effect $(\beta=-0.201$, one - tailed $p<.000)$, the moderating effect of gender on fear of retaliation is significant and negative $(\beta=-0.239$, one tailed $p=.028$ ), and control variables age, position, and country are not significant (two - tailed $p>.05$ ).

Contrary to the logistic model, gender seems to have an additional direct effect on the decision to whistle blow $(\beta=0.367$, one - tailed $p=.047)$. In particular, women seem more likely to choose external channels over internal ones. We also find that our mediation effects are all significant (two - tailed $p<.05$ ), as expected. Controlling for these, the effect of tenure on external whistleblowing is still significant $(\beta=0.153$, two - tailed $p=.022$ ), which is an indication that this finding is not driven by unobserved collinearity in the model.

\section{Discussion}

Before discussing the results, we acknowledge that our research methods are not without limitations. First of all, we asked respondents about their knowledge 
concerning channel options. It might very well be their respective companies have whistleblowing channels established, but employees are not educated about these. We have no means of separating these effects. However, if employees do not know about their options, in the end, it is similar to not having an option at all. We also rely on selfreported data, which is prone to several biases, including self-reporting bias, social desirability bias or common method bias. The interview was carefully conducted, and anonymity assured but we cannot rule out that our data is still influenced by some of these biases. A last concern is that we used English translations of the Chinese and Indian laws. Although these are mostly official translations, some meanings could have been altered without intent by the respective government bodies and as such misinterpreted by the authors of this study. We tried to reduce this concern by consulting other literature by lawyers and found that they corroborate our interpretation of the laws.

This paper is concerned with the status quo of whistleblowing laws, system implementation and whistleblowing behavior in two of the largest economies: China and India.

In regard to whistleblowing laws in the private sector, we found that in both countries listed, companies are obliged to set up reporting systems and to guarantee protective measures. It would be preferable for both countries to extend the introduction of whistleblower systems and whistleblower protection measures to the entire private sector through one comprehensive whistleblowing law. For comprehensive protection, it is important that the existing legal regulations are extended as especially in China certain regulations apply to a small industry only. For legal certainty and comprehensive protection of whistleblowers, it would be important to adopt uniform rules that apply across all sectors. In contrast to India, the many individual regulations in addition to the China-SOX, which is aimed exclusively at listed companies, should be viewed positively. Apart from the Companies Act for listed companies in India, there are hardly any other regulations in India that apply to the private sector. In particular, both countries lack laws that require smaller organizations to implement whistleblowing systems. We currently see this development in the European Union, where companies starting with 50 employees must have set up a whistleblower system (Art. 8 (3) EUWhistleblowing Directive).

In order to assess how these laws translate into the corporate world, we surveyed 942 employees in private sector companies across China and India, which reveals differences in whistleblowing system implementation. In particular, it seems that Indian companies more thoroughly implement whistleblowing channels than their Chinese counterparts. However, the differences become smaller for larger companies. Such large enterprises have thoroughly implemented whistleblowing systems throughout in both countries.

Turning to channel preferences, we find that internal channels are preferred over external ones, as suggested by literature. In particular, an internal ombudsperson seems to be the first choice for many. This might be an indication that whistleblowers prefer a fast, uncomplicated way to report. It also shows that this preference exists, regardless of nationality or culture. External channels may therefore be viewed as a "last resort" for whistleblowers, which is in line with previous findings (Miceli \& Near, 2002; Nayir \& Herzig, 2012; Park et al., 2008). The preference of Indian employees for use of an internal ombudsperson and external agency are both larger than for Chinese employees. 
This is probably due to the fact that Chinese employees also use web-based systems more regularly. It could also be that Chinese employees feel like they cannot trust an internal ombudsperson as much as Indian employees do, as their identity is somewhat disclosed in these scenarios.

Knowing that internal channels are generally preferred, we looked at reasons why people would nonetheless choose an external channel over any internal one to report suspected misconduct. The main finding of our logit regression and partial least squares models are that fear of retaliation positively impacts use of an external channel, in line with suggestions by other authors for other contexts and cultures (i.e., Rehg et al., 2008) and our hypothesis. This is also in line with many findings that retaliation is one of the major aspects that influence the decision to blow the whistle (Culiberg \& Mihelič, 2017). Perceived fear that the incident would not be properly investigated, that anonymity would not be maintained, or that the whistleblower would be prone to job sanctions, such as mobbing, demotion, or even job loss, all lead to a higher likelihood that the whistleblower chooses an external channel. Companies should clearly focus on reducing that perceived fear if they want reports to happen internally and thus avoid the many negative consequences of an external report. One such way is a positive company culture (Bussmann et al., 2018; Bussmann \& Niemeczek, 2019), whereas legislators might introduce additional laws to disincentivize retaliatory measures.

Employees in larger companies are less likely to choose an external channel. Looking at our review of the legal situation, we find that most laws apply to large companies only. As such, protection of whistleblowers in larger companies could be more thoroughly implemented, which could increase employees trust in these internal systems. In larger companies, it is also more likely that anonymity can be guaranteed, given the large number of employees who could potentially report misconduct. In contrast, employees in smaller companies might either not have as much trust in these systems, feel not protected, given the legal focus on larger companies, or simply fear that anonymous channels are not as secure.

Gender had only a direct effect on channel use in the PLS SEM. We therefore caution that this effect might not be robust. However, women seem to be more likely to use an external channel than male employees. This might be due to power and gender inequalities and fears of discrimination, as is reported in other studies (e.g., Rehg et al., 2008). Internal governance efforts should specifically target women and increase their trust in such systems. However, this can only be achieved alongside a more positive corporate culture that values women, an issue that many companies have only just begun to become aware of in the course of the "me too" movement.

Gender also does, as hypothesized, negatively moderate the positive relationship between retaliation and external whistleblowing. That is, women are less influenced in their decision to report externally when fear of retaliation increases compared to male employees. This might be due to the fact that women in general have been found to experience more retaliation and may anticipate retaliatory actions more often than male employees. This also implies that measures aimed at reducing fear of retaliation have stronger effects on male employees.

While our study gives new insight into the Asian context of whistleblowing, more research is needed. For example, we did not look at other institutional or personal antecedents for external whistleblowing, or additional incentive systems. It would be 
interesting to look at why employees in larger companies are more likely to report internally in more detail. While we gave some initial explanations, we cannot test these ideas in our study. More in-depth research on intrinsic or extrinsic, as well as cultural variables influencing the process might also be insightful. Cross-cultural comparisons especially in regard to gender may be just as interesting. We looked at the legal situation in China and India. But research on regulation beyond these contexts might also reveal new insights, best practice approaches, or lack of regulation.

\section{Conclusion}

This study gives an overview of Chinese and Indian legislation and status quo implementation concerning whistleblowing system implementations and, in addition, gives explanations why whistleblowers in China and India use external whistleblowing channels despite having internal whistleblowing options. Our findings give new insight into the Chinese and Indian business context, using data from actual workforce.

In short, mainly listed companies must have established internal whistleblowing channels in both China and India. And although in China there are isolated regulations affecting the private sector, these are insufficient for comprehensive whistleblower protection. A uniform law is recommendable, which does not differentiate between listed and non-listed companies, but is based, for example, on the size of the company. This should also include smaller companies, as only few have systems established in China. Here, the private sector and authorities need to work in tandem in order to produce more effective and credible protection for whistleblowers.

The use of an external channel is usually associated with more negative and severe impact for the companies concerned. It is therefore in their self-interest to foster the use of internal channels. We show that employees choose external channels when fear of retaliation is high and when they work for smaller companies. In addition, women not only are more likely to choose external channels but also are less influenced by retaliation than their male colleagues. Companies need to comprehensively and thoroughly alleviate the fears employees might have in disclosing misconduct.

Future research should take a closer look at the different external and internal systems and their efficiency, how retaliation can be reduced effectively, and why employees in smaller companies are more likely to report externally. More studies should focus on Asian countries, as our understanding of whistleblowing is still dominated by US samples.

Acknowledgements We are grateful to Prof. Dr. K.-D. Bussmann for providing the data used in this project.

Funding Open Access funding enabled and organized by Projekt DEAL. No financial support was received in connection to this paper. The data used in this paper was acquired in a DFG funded project on corruption, led by Prof. Dr. K.-D. Bussmann. One of the authors (Sebastian Oelrich) is a project member.

Data availability The data is available from the authors upon request. 


\section{Declarations}

Ethics approval All procedures performed in studies involving human participants were in accordance with the ethical standards of the institutional and/or national research committee and with the 1964 Helsinki declaration and its later amendments or comparable ethical standards.

Conflict of interest The authors declare no competing interests.

Open Access This article is licensed under a Creative Commons Attribution 4.0 International License, which permits use, sharing, adaptation, distribution and reproduction in any medium or format, as long as you give appropriate credit to the original author(s) and the source, provide a link to the Creative Commons licence, and indicate if changes were made. The images or other third party material in this article are included in the article's Creative Commons licence, unless indicated otherwise in a credit line to the material. If material is not included in the article's Creative Commons licence and your intended use is not permitted by statutory regulation or exceeds the permitted use, you will need to obtain permission directly from the copyright holder. To view a copy of this licence, visit http://creativecommons.org/licenses/by/4.0/.

\section{References}

ACFE Association of Certified Fraud Examiners. (2020). Report to the nations on occupational fraud and abuse. Austin.

Ahmad, S. A. (2011). Internal auditor and internal whistleblowing intentions: a study of organisational, individual, situational and demographic factors. Dissertation. Edith Cowan University, Australia.

Beller, R. (2011). Whistleblower protection legislation of the East and West: can it really reduce corporate governance - a study of the successes and failures of whistleblower protection legislation in the US and China. NYU Journal of Law \& Business, 7, 873-929.

Bodoff, D., \& Ho, S. Y. (2016). Partial least squares structural equation modeling approach for analyzing a model with a binary indicator as an endogenous variable. Communications of the Association for Information Systems, 38, 23. https://doi.org/10.17705/1CAIS.03823.

Brown, A. J., Rehg, M. T., Uys, T., \& Vandekerckhove, W. (2014). Understandings of whistleblowing: dilemmas of societal culture. In A. J. Brown, D. Lewis, R. Moberly, \& W. Vandekerckhove (Eds.), International handbook of whistleblowing research (pp. 37-70). Edward Elgar.

Bussmann, K.-D., \& Niemeczek, A. (2019). Compliance through company culture and values: an international study based on the example of corruption prevention. Journal of Business Ethics, 157(1), 797-811. https://doi.org/10.1007/s10551-017-3681-5.

Bussmann, K.-D., Niemeczek, A., \& Vockrodt, M. (2018). Company culture and prevention of corruption in Germany, China and Russia. European Journal of Criminology, 15(3), 255-277. https://doi.org/10.1177/ 1477370817731058.

Call, A. C., Martin, G. S., Sharp, N. Y., \& Wilde, J. H. (2018). Whistleblowers and outcomes of financial misrepresentation enforcement actions. Journal of Accounting Research, 56(1), 123-171. https://doi.org/ 10.1111/1475-679X.12177.

Cassematis, P., \& Wortley, R. (2013). Prediction of whistleblowing or non-reporting observation: the role of personal and situational factors. Journal of Business Ethics, 117(3), 615-634. https://doi.org/10.1007/ s10551-012-1548-3.

Chwolka, A., \& Oelrich, S. (2020). Whistleblowing as a means for the prevention and detection of fraud in Germany - amidst heroes and informers. Betriebswirtschaftliche Forschung und Praxis, 72(4), 445-471.

Cochran, W. G. (1950). The comparisons of matched samples. Biometrika, 37, 256-266.

Culiberg, B., \& Mihelič, K. K. (2017). The evolution of whistleblowing studies: a critical review and research agenda. Journal of Business Ethics, 146(4), 878-803.

Dhamija, S., \& Rai, S. (2018). Role of retaliation and value orientation in whistleblowing intentions. Asian Journal of Business Ethics, 7(1), 37-52.

Dworkin, T. M., \& Baucus, M. S. (1998). Internal vs. external whistleblowers: a comparison of whistleblowing processes. Journal of Business Ethics, 17, 1281-1298. https://doi.org/10.1023/A: 1005916210589. 
Freshfields Bruckhaus Deringer (2018). Whistleblower protection: Global guide. Freshfields Bruckhaus Deringer UK LLP.

Gibeaut, J. (2006). Culture clash: other countries don't embrace Sarbanes or America's reverence of whistleblowers. ABA Journal, 92(5), 10-12 https://www.jstor.org/stable/i27846177.

Giriprakash, K. (2019). Why India's whistleblower protection programme is not as effective as that in the US. https://www.thehindubusinessline.com/companies/why-indias-whistleblower-protection-programme-isnot-as-effective-as-that-in-the-us/article29794564.ece\#. Accessed January 3, 2020.

Goel, S. (2014). Protection of whistle-blowers in India: a corporate perspective. SSRN Electronic Journal. https://doi.org/10.2139/ssrn.2530397.

Grant, C. (2002). Whistle blowers: saints of secular culture. Journal of Business Ethics, 39(4), 391-399. https://doi.org/10.1023/A:1019771212846.

Gupta, A. K. (2015). NREGA activists who paid with their lives Lalit Mehta (Jharkhand). https://www. downtoearth.org.in/coverage/nrega-activists-who-paid-with-their-lives-lalit-mehta-jharkhand-4727. Accessed February 10, 2020.

Hair, J. F., Ringle, C. M., \& Sarstedt, M. (2011). PLS-SEM: indeed a silver bullet. Journal of Marketing Theory and Practice, 19(2), 139-152.

Hair, J. F., Hult, G. T. M., Ringle, C. M., \& Sarstedt, M. (2017). A primer on partial least squares structural equation modeling (PLS-SEM) (2nd ed.). Sage.

Hair, J. F., Sarstedt, M., Ringle, C. M., \& Gudergan, S. P. (2018). Advanced issues in partial least squares structural equation modeling. Sage.

Hartman, L., Elm, D., Radin, T., \& Pope, K. R. (2009). Translating corporate culture around the world: a cross-cultural analysis of whistleblowing as an example of how to say and do the right thing. Notizie di POLITEIA, XXV(93), 255-272.

Lewis, D. (2007). Whistleblowing at work: ingredients for an effective procedure. Human Resource Management Journal, 7(4), 5-11.

Lu, Y., \& Ma, D. (2017). "China SOX": what is it and why was it introduced? WSEAS Transactions on Business and Economics, 14, 446-457.

Mesmer-Magnus, J. R., \& Viswesvaran, C. (2005). Whistleblowing in organizations: an examination of correlates of whistleblowing intentions, actions, and retaliation. Journal of Business Ethics, 62(3), 277297. https://doi.org/10.1007/s10551-005-0849-1.

Miceli, M. P., \& Near, J. P. (2002). What makes whistle-blowers effective? Three field studies. Human Relations, 55(4), 455-479. https://doi.org/10.1177/0018726702055004463.

Moberly, R. (2007). Unfulfilled expectations: an empirical analysis of why Sarbanes-Oxley whistle-blowers rarely win. William and Mary Law Review, 49(1), 65-155.

Mogielnicki, M. S. (2011). Hunting for 'bounty' and finding 'moral autonomy': the Dodd-Frank Act expansion of whistle blower protection. Academy of Business Research, 11, 74-84.

Moy, G. (2018). The role of whistleblowers in protecting the safety and integrity of the food supply. npj Science of Food, 2, 1-5. https://doi.org/10.1038/s41538-018-0017-5.

Muttathil, M. S. (2018). An Indian Perspective on whistleblowing. https://www.accdocket.com/articles/anindian-perspective-on-whistleblowing.cfm. Accessed May 6, 2019.

Nayir, D. Z., \& Herzig, C. (2012). Value orientations as determinants of preference for external and anonymous whistleblowing. Journal of Business Ethics, 107(2), 197-213. https://oi.org/10.1007/ s10551-011-1033-4.

Near, J. P., \& Miceli, M. P. (1985). Organizational dissidence: the case of whistle-blowing. Journal of Business Ethics, 4, 1-16. https://doi.org/10.1007/BF00382668.

OECD. (2019). SIGI 2019 Global Report: transforming challenges into opportunities. Social Institutions and Gender Index, OECD Publishing. https://doi.org/10.1787/bc56d212-en.

Oelrich, S. (2019). Making regulation fit by taking irrationality into account: the case of the whistleblower. Business Research, 12(1), 175-207. https://doi.org/10.1007/s40685-019-0094-6.

Oelrich, S. (2020). Remarks on "Role of retaliation and value orientation in whistleblowing intentions" by Dhamija \& Rai (2018). Asian Journal of Business Ethics, 9(1), 23-27. https://doi.org/10.1007/s13520019-00097-0.

Oelrich, S. (2021). Intention without action? Differences between whistleblowing intention and behavior on corruption and fraud. Business Ethics, the Environment \& Responsibility, online first. https://doi.org/10. 1111/beer.12337.

Park, H., \& Blenkinsopp, J. (2009). Whistleblowing as planned behavior-a survey of South Korean police officers. Journal of Business Ethics, 85(4), 545-556. https://doi.org/10.1007/s10551-008-9788-y. 
Park, H., Blenkinsopp, J., Oktem, M. K., \& Omurgonulsen, U. (2008). Cultural orientation and attitudes towards different forms of whistleblowing: a comparison of South Korea, Turkey, and the U.K. Journal of Business Ethics, 82(4), 929-939. https://doi.org/10.1007/s10551-007-9603-1.

van de Pol, M., Wu, V., \& Hui, S. (2016). New rules offer greater protection and incentives to whistleblowers in China. https://globalcompliancenews.com/new-rules-offer-greater-protection-and-incentives-towhistleblowers-in-china-20160504/ Accessed August 6, 2019.

Rehg, M. T., Miceli, M. P., Near, J. P., \& Van Schotter, J. R. (2008). Antecedents and outcomes of retaliation against whistleblowers: gender differences and power relationships. Organization Science, 19(2), 221240. https://doi.org/10.1287/orsc.1070.0310.

Rothschild, J., \& Miethe, T. D. (1999). Whistle-blower disclosures and management retaliation: the battle to control information about organization corruption. Work and Occupations, 26(1), 107-128. https://doi. org/10.1177/0730888499026001006.

Sims, R. L., \& Keenan, J. P. (1998). Predictors of external whistleblowing: organizational and intrapersonal variables. Journal of Business Ethics, 17(1), 411-421. https://doi.org/10.1023/A:1005763807868.

The World Bank (2020). Country reports. For China: https://www.worldbank.org/en/country/china/overview. For India: https://www.worldbank.org/en/country/india/overview Accessed September 20, 2020.

Transparency International (2020). Corruption Perceptions Index 2019. Online: https:/www.transparency.org/ en/cpi/2019 Accessed September 20, 2020.

Wilde, J. H. (2017). The deterrent effect of employee whistleblowing on firms' financial misreporting and tax aggressiveness. The Accounting Review, 92(5), 247-280. https://doi.org/10.2308/accr-51661.

$\mathrm{Wu}, \mathrm{V} .$, \& Li, M. (2015). Managing internal whistleblower complaints in China: challenges and strategies. https:/globalcompliancenews.com/managing-internal-whistleblower-complaints-in-china-challengesand-strategies/\#. Accessed July 30, 2019.

Publisher's note Springer Nature remains neutral with regard to jurisdictional claims in published maps and institutional affiliations. 